
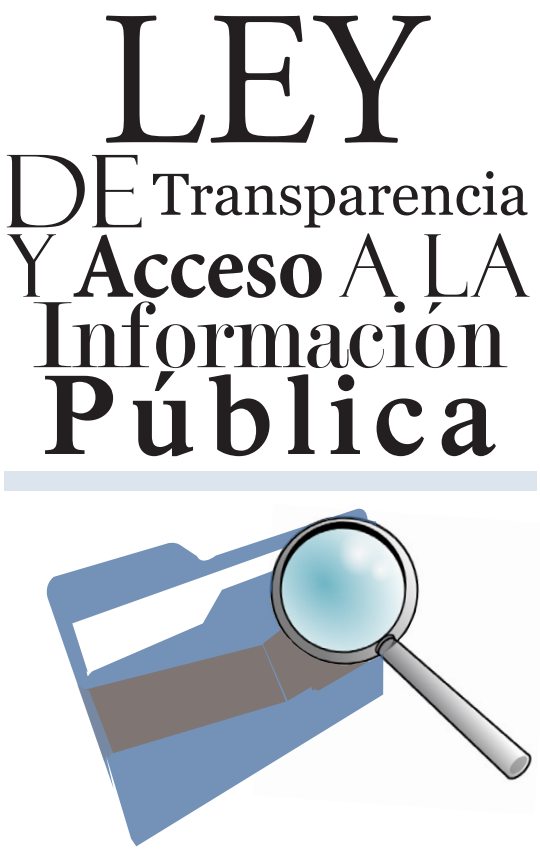



\section{DECRETO LEGISLATIVO No. 170 - 2006}

\section{Diario Oficial La Gaceta, 30 de diciembre de 2006}

\section{EL CONGRESO NACIONAL,}

CONSIDERANDO: Que Honduras es un Estado de Derecho en donde los funcionarios son depositarios de la autoridad, responsables legalmente por su conducta oficial, sujetos a la Ley y que tienen la obligación de cumplir sus funciones con eficiencia, ética y responsabilidad social;

CONSIDERANDO: Que la transparencia y la rendición de cuentas son garantías para un mejor desempeño del servidor público y del gobierno en general y, además, condiciones necesarias para una efectiva participación ciudadana en la construcción de una auténtica democracia;

CONSIDERANDO: Que el derecho de acceso a la información pública es garantía de transparencia para que los ciudadanos puedan fiscalizar y exigir cuentas a los servidores públicos, a cada paso del proceso y en cualquier momento, y, además, constituye un medio eficaz contra la corrupción;

CONSIDERANDO: Que cuanto mayor sea el conocimiento de los ciudadanos sobre la acción pública, mayor será su participación en la toma de decisiones y su confianza en la función gubernamental;

CONSIDERANDO: Que el pueblo hondureño tiene el derecho de acceso a la información, así como a la transparencia y rendición de cuentas de la gestión pública y, que además, el Estado ha ratificado la Convención Interamericana contra la Corrupción en la que se reconocen expresamente estos derechos;

\section{POR TANTO,}

\section{DECRETA:}

La siguiente: 


\title{
LEY DE TRANSPARENCIA Y ACCESO \\ A LA INFORMACIÓN PÚBLICA
}

\section{CAPÍTULO I}

\section{DISPOSICIONES GENERALES}

\begin{abstract}
ARTíCULO 1.- NATURALEZA Y FINALIDAD DE LA LEY. Esta Ley es de orden público e interés social. Tiene por finalidad el desarrollo y ejecución de la política nacional de transparencia, así como el ejercicio del derecho de toda persona al acceso a la información pública para el fortalecimiento del Estado de Derecho y consolidación de la democracia mediante la participación ciudadana.
\end{abstract}

ARTíCULO 2.- OBJETIVOS DE LA LEY. Son objetivos de esta Ley establecer los mecanismos para:

1) Garantizar el ejercicio del derecho que tienen los ciudadanos a participar en la gestión de los asuntos públicos;

2) Promover la utilización eficiente de los recursos del Estado;

3) Hacer efectiva la transparencia en el ejercicio de las funciones públicas y en las relaciones del Estado con los particulares;

4) Combatir la corrupción y la ilegalidad de los actos del Estado;

5) Hacer efectivo el cumplimiento de la rendición de cuentas por parte de las entidades y servidores públicos; y,

6) Garantizar la protección, clasificación y seguridad de la información pública y el respeto a las restricciones de acceso en los casos de:

a) Información clasificada como reservada por las entidades públicas conforme a esta Ley;

b) Información entregada al Estado por particulares, en carácter de confidencialidad;

c) Los datos personales confidenciales; $y$,

d) La secretividad establecida por la Ley. 
ARTíCULO 3.- DEFINICIONES. Para los efectos de la presente Ley, se entiende por:

1) Transparencia: El conjunto de disposiciones y medidas que garantizan la publicidad de la información relativa de los actos de las instituciones obligadas y el acceso de los ciudadanos a dicha información.(R)

2) Publicidad: El deber que tienen las instituciones públicas de dar a conocer a la población la información relativa a sus funciones, atribuciones, actividades y a la administración de sus recursos;

3) Derecho de Acceso a la Información Pública: El derecho que tiene todo ciudadano para acceder a la información generada, administrada o en poder de las instituciones obligadas previstos en la presente Ley, en los términos y condiciones de la misma;

4) Instituciones Obligadas: a) El Poder Legislativo, el Poder Judicial, el Poder Ejecutivo, las instituciones autónomas, las municipalidades y los demás órganos e instituciones del Estado; b) Las Organizaciones No Gubernamentales (ONG'S), Las Organizaciones Privadas de Desarrollo (OPD's) y en general todas aquellas personas naturales o jurídicas que a cualquier título reciban o administren fondos públicos, cualquiera que sea su origen, sea nacional o extranjero o sea por si misma o a nombre del Estado o donde éste haya sido garante, $y$ todas aquellas organizaciones gremiales que reciban ingresos por la emisión de timbres, por la retención de bienes o que estén exentos del pago de impuestos;

5) Información Pública: Todo archivo, registro, dato o comunicación contenida en cualquier medio, documento, registro impreso, óptico o electrónico u otro que no haya sido clasificado como reservado se encuentre en poder de las Instituciones Obligadas que no haya sido previamente clasificada como reservada y que pueda ser reproducida. Dicha información incluirá la contenida en los expedientes, reportes, estudios, actas, resoluciones, oficios, decretos, acuerdos, directrices, estadística, licencias de todo tipo, personalidades jurídicas, presupuestos, liquidaciones presupuestarias, financiamientos, donaciones, adquisiciones de bienes, suministros y servicios, y todo registro que documente el ejercicio de facultades, derechos y obligaciones de las Instituciones Obligadas sin importar su fuente o fecha de elaboración;

6) Información Reservada: La información pública clasificada como tal por esta Ley, la clasificada como de acceso restringido por otras leyes y por resoluciones particulares de las instituciones del sector público; 
7) Datos Personales confidenciales: Los relativos al origen étnico o racial, características físicas, morales o emocionales, domicilio particular, número telefónico particular, dirección electrónica particular, participación, afiliación a una organización política, ideología política, creencias religiosas o filosóficas, estados de salud, físicos o mentales, el patrimonio personal o familiar y cualquier otro relativo al honor, la intimidad personal, familiar o la propia imagen;

8) Servidor Público: Cualquier funcionario o empleado del Estado o de cualquiera de sus entidades, en todos sus niveles jerárquicos, incluidos los que hayan sido seleccionados, nombrados, contratados o electos para desempeñar actividades o funciones que sean competencia del Estado, de sus entidades o al servicio de ésta, incluyendo aquellas personas que las desempeñen con carácter ad-honorem.(R)

9) Información Confidencial: La información entregada al Estado por particulares a la que la Ley le atribuya carácter confidencial, incluyendo las ofertas selladas en concursos y licitaciones antes de la fecha señalada para su apertura; $y$,

10) Recursos y Fondos del Estado: Bienes financieros y no financieros pertenecientes al Estado.

\section{ARTíCULO 4.- DEBER DE INFORMAR Y DERECHO AL ACCESO A LA INFORMACIÓN PÚBLICA. Todas las instituciones obligadas deberán publicar la información relativa a su gestión o, en su caso, brindar toda la información concerniente a la aplicación de los fondos públicos que administren o hayan sido garantizados por el Estado. \\ Sin perjuicio de lo previsto en la Ley de Contratación del Estado en relación con las publica- ciones, todos los procedimientos de selección de contratistas y los contratos celebrados, se divulgarán obligatoriamente en el sitio de Internet que administre la Oficina Normativa de Contratación y Adquisiciones (ONCAE). A este efecto, los titulares de los órganos o institu- ciones públicas quedan obligados a remitir la información respectiva.}

A su vez, toda persona natural o jurídica, tiene derecho a solicitar y a recibir de las Instituciones Obligadas, información completa, veraz, adecuada y oportuna en los límites y condiciones establecidos en esta Ley.

ARTíCULO 5.- SOPORTE HUMANO Y TÉCNICO. Para el cumplimiento de su deber de transparencia, las Instituciones Obligadas deberán mantener subsistemas con suficiente soporte humano y técnico, que permitan la sistematización de la información, la prestación de un servicio de consulta y el acceso por los ciudadanos, así como su publicación cuando sea 
procedente a través de los medios electrónicos o escritos disponibles. Para ese efecto, cada institución designará un Oficial de Información Pública responsable de dicho subsistema y suministre la información solicitada siempre y cuando no esté declarada como reservada de conformidad con el Artículo 17 de la presente Ley.

Cada Institución creará una partida presupuestaria suficiente para asegurar su funcionamiento.

\section{ARTíCULO 6.- PROMOCIÒN DE UNA CULTURA DE TRANSPARENCIA Y APERTURA DE LA INFORMACIÓN.}

Las Instituciones Obligadas deberán capacitar y actualizar de forma permanente a sus servidores públicos en la cultura de acceso a la información, la cultura de apertura informativa, transparencia de la gestión pública y el ejercicio de la garantía de Hábeas Data.

Las Instituciones Obligadas deberán asimismo capacitar sobre el contenido de esta Ley y los procedimientos específicos definidos por dicha Institución para ser efectivo su cumplimiento. La Secretaría de Estado en el Despacho de Educación por conducto de las instituciones de educación formal o no formal y las universidades públicas y privadas, incluirán contenidos sobre esta materia en los planes o programas de estudio.

\section{ARTÍCULO 7.- TRANSPARENCIA EN RELACIONES COMERCIALES Y CONTRACTUALES CON EL ESTADO.}

Los particulares, el Estado y todas las instituciones públicas, están obligados a regir sus relaciones comerciales con las Instituciones Obligadas por los principios de la buena fe, la transparencia y la competencia leal cuando participen en procesos de licitaciones, contrataciones, concesiones, ventas, subastas de obras o concursos. Están igualmente obligados a cumplir con las condiciones de la contratación, los términos de referencia, las especificaciones o pliegos de condiciones, documentos y condiciones de contratación establecidas en la Ley.

Los contratos deben incluir cláusulas de integridad que obliguen a los particulares a observar reglas de conducta ética en todo este proceso. La Oficina Normativa de Contratación y Adquisiciones (ONCAE) en coordinación con el Instituto de Acceso a la Información Pública (IAIP) y el Consejo Nacional Anticorrupción (CNA) elaborarán los formatos de dichas cláusulas conforme a lo prescrito en la Ley de Contratación del Estado.

Igual obligación deberán tener las Instituciones del Estado de regir sus relaciones comerciales con los particulares. 


\title{
CAPÍTULO II
}

\section{EL INSTITUTO DE ACCESO A LA INFORMACIÓN PÚBLICA}

\begin{abstract}
ARTÍCULO 8.- CONSTITUCIÓN Y FINALIDAD DEL INSTITUTO DE ACCESO A LA INFORMACIÓN PÚBLICA. El Instituto de Acceso a la Información Pública (IAIP), es un órgano desconcentrado de la administración pública, con independencia operativa, decisional y presupuestaria, responsable de promover y facilitar el acceso de los ciudadanos a la información pública, así como de regular y supervisar los procedimientos de las instituciones obligadas en cuanto a la protección, clasificación y custodia de la información pública, de acuerdo a esta Ley. La Presidencia de la República apoyará el funcionamiento de este Instituto y actuará como órgano de enlace la Secretaría de Estado en el Despacho de la Presidencia.
\end{abstract}

ARTíCULO 9.- INTEGRACIÓN Y DIRECCIÓN. El Instituto de Acceso a la Información Pública (IAIP) estará integrado por tres (3) comisionados, electos por el Congreso Nacional, por las dos terceras partes de votos de la totalidad de sus miembros, escogidos de entre candidatos que se propongan así:

1) Dos (2), el Presidente de la República;

2) Dos (2), la Procuraduría General de la República (PGR);

3) Dos (2), el Comisionado Nacional de los Derechos Humanos;

4) Dos (2), el Foro Nacional de Convergencia (FONAC); y,

5) Dos (2), por el Tribunal Superior de Cuentas

Durarán en sus cargos cinco (5) años, y sólo podrán ser sustituidos por imposibilidad legal o natural, cuando sus actuaciones entren en conflictos con la naturaleza de las funciones del Instituto.

La presidencia del Instituto de Acceso a la Información Pública (IAIP), ostentará Representación Legal. La designación del Presidente será hecha por el Congreso Nacional. Los comisionados resolverán colegiadamente todos sus asuntos. 


\section{ARTíCULO 10.- REQUISITOS DE LOS COMISIONADOS. Para ser Comisionado se requiere:}

1) Ser hondureño;

2) Mayor de treinta y cinco (35) años;

3) No haber sido condenado penalmente;

4) Contar con una experiencia profesional no menor de diez (10) años de servicio público, o académico; y,

5) Ser de reconocida honorabilidad y ostentar título universitario.

ARTÍCULO 11.- FUNCIONES Y ATRIBUCIONES DEL IAIP. EI IAIP tendrá las funciones y atribuciones siguientes:

1) Conocer y resolver los recursos de revisión interpuestos por solicitantes en el marco de esta Ley;

2) Establecer los manuales e instructivos de procedimiento para la clasificación, archivo, custodia y protección de la información pública, que deban aplicar las instituciones públicas conforme las disposiciones de esta Ley;

3) Apoyar las acciones y el Archivo Nacional en cuanto a la formación y protección de los fondos documentales de la Nación;

4) Establecer los criterios y recomendaciones para el funcionamiento del Sistema Nacional de Información Pública;

5) Aplicar el marco sancionario de la presente Ley;

6) Realizar las gestiones estrictamente administrativas y necesarias para garantizar el ideracho de acceso a la información por parte de los ciudadanos;

7) Reglamentar, planificar, organizar y Ilevar a cabo su funcionamiento interno;

8) Presentar un informe de actividades en forma semestral a la Presidencia de la 
República y al Congreso Nacional;

9) Realizar actividades de promoción y divulgación en cuanto al ejercicio del derecho de acceso a la información pública. Operar un sistema de información en relación a su funcionamiento;

10) Otras afines y necesarias para alcanzar las finalidades del IAIP; $y$,

11) Garantizar que se publique la información que debe ser difundida de oficio según el Artículo 13 de esta Ley. (R)

\section{CAPÍTULO III}

\section{SISTEMA NACIONAL DE INFORMACIÓN}

ARTíCULO 12.- DEL SISTEMA. El Sistema Nacional de Información Pública tendrá como propósito integrar, sistematizar, publicar y dar acceso a la información pública por medio de todos los subsistemas de información existentes, los cuales deberán integrarse en formatos uniformes de acuerdo a las normas y procedimientos establecidos en el mismo.

Los procesos para la organización y funcionamiento de dicho sistema serán establecidos por el Instituto de Acceso a la Información Pública (IAIP) en coordinación con el Tribunal Superior de Cuentas, la Secretaría de Estado en el Despacho de Finanzas y la Comisión de Modernización del Estado.

ARTÍCULO 13.- INFORMACIÓN QUE DEBE SER DIFUNDIDA DE OFICIO. Toda Institución Obligada está en el deber de difundir de oficio y actualizar periódicamente a través de medios electrónicos o instrumentos computarizados; a falta de éstos, por los medios escritos disponibles, la información siguiente:

1) Su estructura orgánica, sus funciones, las atribuciones por unidad administrativa, los servicios que presta, las tasas y derechos y los procedimientos, requisitos y formatos para acceder a los mismos;

2) Las Leyes, reglamentos, circulares y demás disposiciones de observancia general que rigen su funcionamiento; 
3) Las políticas generales, los planes, programas y proyectos, informes, actividades, los estados financieros y las liquidaciones presupuestarias trimestrales por programas;

4) Toda la información catastral que posean y su vinculación con el Registro de la Propiedad Inmueble;

5) Los registros públicos de cualquier naturaleza;

6) El Diario Oficial La Gaceta actualizado;

7) La remuneración mensual de los servidores públicos por puesto, incluyendo otros pagos asociados al desempeño del puesto;

8) Los presupuestos, un informe trimestral y otro anual de la ejecución presupuestaria, que incluya el detalle de las transferencias, los gastos, la inversión física y financiera, la deuda y la morosidad;

9) Las contrataciones, concesiones, ventas, subastas de obras, convocatorias a concurso, licitación de obras públicas y suministros, los contratos de consultoría, las actas de apertura de ofertas y adjudicación, ampliaciones, prórrogas y declaratorias de compras directas, así como sus resultados;

10) Los mecanismos que permitan la participación ciudadana en la toma de decisiones;

11) El nombre de los servidores públicos encargados de gestionar y resolver las solicitudes de información pública, la dirección, teléfono y dirección electrónica de su centro de trabajo;

12) Los Decretos Ejecutivos, Acuerdos y Resoluciones firmes que emita el Poder Ejecutivo, incluyendo las instituciones descentralizadas;

13) El Congreso Nacional, publicará además, las resoluciones que resulten de las mociones y decretos que se aprueben; asimismo publicará las iniciativas de leyes y sus respectivos dictámenes, y opiniones, para lo cual, quienes las presenten deberán entregarlas a la Secretaría por escrito y en formato electrónico para que proceda a publicarlas en el plazo máximo de diez (10) días, y difundir por Internet las sesiones del pleno del 
Congreso Nacional y de las comisiones;

14) El Poder Judicial, publicará además, las sentencias judiciales firmes que hayan causado estado o ejecutoria, sin perjuicio, del derecho que tienen las partes para oponerse a la publicación de sus datos personales;

15) El Tribunal Superior de Cuentas, publicará además los informes definitivos de las intervenciones fiscalizadoras practicadas; así como la publicación de las resoluciones una vez que hayan quedado firmes;

16) La Procuraduría General de la República, publicará además la relación de los juicios en que sean parte las instituciones públicas y las sentencias definitivas recaídas en ellos;

17) Las municipalidades publicarán además una relación de los juicios en que sean parte y las sentencias definitivas recaídas en ellas las resoluciones y actas de las sesiones de la Corporación Municipal;

18) Las instituciones respectivas, publicarán además las estadísticas y la información relativa al comportamiento macroeconómico y financiero del Estado que generen o manejen; $y$,

19) La información sobre actividades de empresas privadas que suministren bienes y servicios públicos con carácter de exclusividad o que celebren contratos financiados con recursos o fondos del Estado, será divulgada por medio de la entidad pública con la cual se hayan celebrado los contratos respectivos.

ARTíCULO 14.- ENTREGA Y USO DE LA INFORMACIÓN. La Información Pública deberá proporcionarse al solicitante o usuario en el estado o formato en que se encuentre disponible. En caso de inexistencia de la información solicitada, se le comunicará por escrito este hecho al solicitante.

Los solicitantes o usuarios no podrán exigir a las Instituciones Obligadas que efectúen evaluaciones o análisis de la información que posean.

Los solicitantes o usuarios serán directamente responsables por el uso, manejo y difusión de la información pública a la que tengan acceso. 


\begin{abstract}
ARTíCULO 15.- FORMA DE ENTREGA DE LA INFORMACIÓN SOLICITADA. La información solicitada por el ciudadano podrá entregarse, a su requerimiento, en forma personal, por medio de fax, servicio postal o por medios electrónicos protegiendo la integridad de la información.

El acceso público a la información es gratuito, no obstante, la institución pública está autorizada para cobrar y percibir únicamente los costos de la reproducción previamente establecidos por la institución respectiva.
\end{abstract}

ARTíCULO 16.- RESTRICCIÓN DEL ACCESO A LA INFORMACIÓN. El ejercicio del derecho de acceso a la información pública estará restringido cuando:

1) Cuando lo establezca la Constitución, las leyes, los tratados, o sea declarada como reservada con sujeción a lo dispuesto en los Artículos 17 y 18 de esta Ley;

2) Se reconozca como información reservada o confidencial de acuerdo con el Artículo 3, numerales 7) y 9) de la presente Ley;

3) Todo lo que corresponda a instituciones y empresas del sector privado, que no esté comprendido en obligaciones que señale esta Ley y leyes especiales; y,

4) El derecho de acceso a la información pública no será invocado en ningún caso para exigir la identificación de fuentes periodísticas dentro de los órganos del sector público, ni la información que sustente las investigaciones e información periodística que haya sido debidamente publicadas y que obre en los archivos de las empresas de medios de comunicación.

\title{
ARTíCULO 17.- CLASIFICACIÓN DE LA INFORMACIÓN COMO RESERVADA. Sin perjuicio
} de lo dispuesto en la Ley sobre la secretividad de datos y procesos y confidencialidad de datos personales y de información entregada por particulares al Estado bajo reserva; la clasificación de la información pública como reservada procede cuando el daño que puede producirse, es mayor que el interés público de conocer la misma o cuando la divulgación de la información ponga en riesgo o perjudique:

1) La seguridad del Estado;

2) La vida, la seguridad y la salud de cualquier persona, la ayuda humanitaria, los in- 
tereses jurídicamente tutelados a favor de la niñez y de otras personas o por la garantía de Hábeas Data;

3) El desarrollo de investigaciones reservadas en materia de actividades de prevención, investigación o persecución de los delitos o de la impartición de justicia;

4) El interés protegido por la Constitución y las Leyes;

5) La conducción de las negociaciones y las relaciones internacionales; y,

6) La estabilidad económica, financiera o monetaria del país o la gobernabilidad.

\begin{abstract}
ARTÍCULO 18.- ACUERDO DE CLASIFICACIÓN DE LA INFORMACIÓN COMO RESERVADA. Para clasificar la información como reservada, en base a cualquiera de las causales enumeradas en el artículo anterior, el titular de cualquier órgano público, deberá elevar la petición por medio de la instancia de máxima jerarquía de la institución a la cual pertenezca, quien de considerarlo pertinente, emitirá el respectivo acuerdo de clasificación de la información, debidamente motivado y sustentado.
\end{abstract}

El titular respectivo debe remitir copia de la petición al Instituto de Acceso a la Información Pública. Cuando éste considere que la información cuya clasificación se solicita no se encuentra en ninguno de los supuestos del artículo anterior, lo hará del conocimiento del superior respectivo y éste denegará la solicitud del inferior. Si, contrariando esta opinión, se emitiere el acuerdo de clasificación, éste será nulo de pleno derecho.

ARTÍCULO 19.- DURACIÓN DE LA RESERVA. La información clasificada como reservada, tendrá este carácter mientras subsista la causa que dio origen a la reserva, fuera de esta circunstancia, la desclasificación de la reserva solo tendrá lugar, una vez que se haya cumplido un término de diez (10) años, contados a partir de la declaratoria de reserva, salvo que exista una orden judicial, en cuyo caso, la reclasificación se circunscribirá al caso específico y para uso exclusivo de la parte interesada, es decir bajo reserva de uso público.

\title{
CAPITULO IV EJERCICIO DEL DERECHO DE ACCESO A LA INFORMACIÓN PÚBLICA
}

ARTíCULO 20.- SOLICITUD. La solicitud de acceso a la información pública deberá presentarse por escrito o por medios electrónicos, indicándose con claridad los detalles específicos 
de la información solicitada, sin motivación ni formalidad alguna. Esta disposición no facultará al solicitante para copiar total o parcialmente las bases de datos.

En caso de que el solicitante sea persona jurídica, deberá acreditar además de su existencia legal, el poder suficiente de quien actúa a nombre de ésta.

ARTíCULO 21.- FUNDAMENTACIÓN Y TÉRMINO PARA RESOLVER. Presentada la solicitud, se resolverá en el término de diez (10) días, declarándose con o sin lugar la petición. En casos debidamente justificados, dicho plazo podrá prorrogarse por una sola vez y por igual tiempo.

En caso de denegatoria de la información solicitada, se deberán indicar por escrito al solicitante los fundamentos de la misma.

\section{ARTÍCULO 22.- ACCESO A LA INFORMACIÓN POR PARTE DE LOS PERIODISTAS. LaS} autoridades están obligadas a dar protección y apoyo a los periodistas en el ejercicio de su profesión, proporcionándoles la información solicitada sin más restricciones que las contempladas en esta Ley y en las demás leyes de la República.

\section{CAPITULO V \\ DATOS PERSONALES Y HÁBEAS DATA}

ARTíCULO 23.- HÁBEAS DATA. Se reconoce la garantía de Hábeas Data.

ARTíCULO 24.- SISTEMATIZACIÓN DE ARCHIVOS PERSONALES Y SU ACCESO. Los datos personales serán protegidos siempre. El interesado o en su caso el Comisionado Nacional de los Derechos Humanos por si o en representación de la parte afectada y el Ministerio Público podrán incoar las acciones legales necesarias para su protección.

El acceso a los datos personales únicamente procederá por decreto judicial o a petición de la persona cuyos datos personales se contienen en dicha información o de sus representantes o sucesores.

ARTíCULO 25.- PROHIBICIÓN DE ENTREGA DE INFORMACIÓN. Ninguna persona podrá obligar a otra a proporcionar datos personales que puedan originar discriminación o causar daños o riesgos patrimoniales o morales de las personas. 


\section{CAPITULO VI}

\section{PROCEDIMIENTOS, INFRACCIONES Y SANCIONES}

\section{ARTÍCULO 26.- PROCEDIMIENTOS A SEGUIR ANTE LA DENEGATORIA DE ENTREGA DE} LA INFORMACIÓN. Cuando la solicitud de información se hubiere denegado o cuando no se hubiere resuelto en el plazo establecido en el Artículo 21, el solicitante podrá acudir ante el Instituto de Acceso a al Información Pública (IAIP) para solicitar la revisión de la denegatoria. La resolución de éste se emitirá dentro de un plazo de diez (10) días, contado a partir de la presentación de la solicitud. Contra esta resolución solo procederá el recurso de amparo en los términos de la Ley de Justicia Constitucional.

ARTÍCULO 27.- INFRACCIONES ADMINISTRATIVAS. Sin perjuicio de la responsabilidad civil, incurrirá en infracción a esta Ley, quien:

1. Estando obligados por Ley, no proporcionare de oficio o se negare a suministrar la información pública requerida en el tiempo estipulado o de cualquier manera obstaculizare su acceso;

2. Copie, capte, consulte, divulgue o comercialice información reservada cuando la Ley lo prohíbe o en el caso de datos personales, se negare a proporcionarlos a su legítimo titular, sus sucesores o autoridad competente;

3. Elimine, suprima o altere, información pública o reservada y los instrumentos que la contengan, sin seguir el procedimiento de depuración previsto en el Artículo 32 de la presente Ley;

4. Fuera de los casos previstos en esta Ley, recoja, capte, transmita o divulgue datos personales, o se niegue a rectificarlos, actualizarlos o eliminar información falsa en los datos personales confidenciales contenidos en cualquier archivo, registro o base de datos de las Instituciones Obligadas por esta Ley; y,

5. Estando obligado, de conformidad con el Artículo 4, segundo párrafo, de esta Ley, no envíe la información relativa a los procedimientos de contratación y las contrataciones mismas a la Oficina Normativa de Contratación y Adquisiciones.

ARTÍCULO 28.- SANCIONES ADMINISTRATIVAS. Sin perjuicio de la responsabilidad civil, 
las infracciones no constitutivas de delito, serán sancionadas con amonestación por escrito, suspensión, multa, cesantía o despido. Las multas de entre medio salario hasta cincuenta (50) salarios mínimos mensuales, serán impuestos por el Instituto de Acceso a la Información Pública, (IAIP), dependiendo de la gravedad de la infracción, debiendo ser enterados dichos valores en la Tesorería General de la República.

ARTíCULO 29.- DELITOS Y SANCIONES PENALES. Cuando la infracción a esta Ley sea constitutiva de delito, será sancionada conforme a lo establecido en los Delitos contra la Administración Pública del Código Penal.

\section{CAPITULO VII}

\section{ÓRGANO DE VIGILANCIA Y SISTEMA NACIONAL DE ARCHIVO}

ARTíCULO 30.- ÓRGANO DE VIGILANCIA. Corresponde al Consejo Nacional Anticorrupción (CNA) velar por la correcta aplicación de la presente Ley, para lo cual tendrá acceso a las instituciones y a la información que no sea clasificada como reservada, confidencial, datos personales confidenciales o secreta de acuerdo a la Ley.

ARTíCULO 31.- COMISIÓN LEGISLATIVA DE SEGUIMIENTO. El Congreso Nacional, en cumplimiento de sus funciones, constituirá una Comisión Especial de Seguimiento de la Ley de Transparencia y Acceso a la Información, la cual recibirá informes trimestrales por parte de las instituciones públicas y formulará recomendaciones al respecto, pudiendo requerir para ello su presencia ante la Comisión.

ARTíCULO 32.- DEPURACIÓN. Cada institución pública está en la obligación de conservar y custodiar la información pública, incluyendo la reservada, obtenida o generada con motivo del cumplimiento de sus funciones, mientras conserve valor administrativo o jurídico o en su defecto, por un período no menor de cinco (5) años, se exceptúa de esta regla la información clasificada como reservada la cual sólo podrá ser depurada, transcurrido un año después de vencido el período durante el cual se mantuvo en reserva.

Vencido el plazo de conservación, la información pública deberá ser sometida al procedimiento de depuración que realice una Comisión de Depuración Documental integrada por delegados de las instituciones siguientes: 
1. Instituto de Acceso a la Información Pública (IAIP);

2. Tribunal Superior de Cuentas;

3. La Procuraduría General de la República;

4. Archivo Nacional, como receptor de la documentación depurada; y,

5. En su caso, un delegado de la institución pública cuya información es depurada.

Esta Comisión emitirá las listas de clasificación, registro, catalogación de la documentación que deba resguardarse por su valor histórico, legal y administrativo consiguiente. En ningún caso podrá destruirse la información pública y reservada sin cumplir con este procedimiento de depuración.

ARTÍCULO 32-A.- INFORMACIÓN PÚBLICA ANTERIOR A LA LEY. La información pública anterior a esta Ley, no podrá ser destruida, alterada ni cambiada bajo ninguna circunstancia so pena de las sanciones que la Ley establece.

ARTíCULO 33.- DERECHOS ACCESORIOS. El derecho de acceso a la información, no perjudica, limita o sustituye el derecho a presenciar u observar los actos de la administración pública, en la forma permitida por la Ley; así como participar en audiencias o cabildos abiertos para recibir información.

\section{CAPITULO VIII}

\section{DISPOSICIONES TRANSITORIAS Y FINALES}

\section{SECCIÓN PRIMERA}

\section{DISPOSICIONES TRANSITORIAS}

ARTíCULO 34.- REGLAMENTACIÓN. El Reglamento de esta Ley será emitido por el Instituto de Acceso a la Información Pública (IAIP) dentro del plazo de tres (3) meses contados a partir de la vigencia de este Decreto, con conocimiento del Tribunal Superior de Cuentas.

ARTíCULO 35.- ADECUACIÓN A LA LEY. Las instituciones obligadas deberán ajustar su or- 
ganización y funcionamiento, así como ejecutar las acciones necesarias para el cumplimiento efectivo de la presente Ley en forma gradual dentro de un plazo máximo de un año, contado a partir de la vigencia de esta Ley.

\section{ARTÍCULO 36.- ASIGNACIONES PRESUPUESTARIAS AL INSTITUTO DE ACCESO A LA INFORMACIÓN PÚBLICA (IAIP). Anualmente, la Secretaría de Estado en el Despacho de Finanzas incluirá en el Proyecto de Presupuesto General de Ingresos y Egresos de la República las asignaciones presupuestarias necesarias para que el Instituto de Acceso a la Información Pública (IAIP) pueda garantizar el efectivo cumplimiento de esta Ley.}

\section{SECCIÓN SEGUNDA}

\section{DISPOSICIONES FINALES}

ARTíCULO 37.- PLAZOS. Cuando esta Ley se refiera a plazos o términos, consistirán en días hábiles.

ARTÍCULO 38.- CALIDAD ESPECIAL DEL INSTITUTO. El Instituto de Acceso a la Información Pública (IAIP) será el órgano responsable de cumplir con las obligaciones que la Convención Interamericana contra la Corrupción y la Convención de las Naciones Unidas contra la Corrupción, imponen al Estado de Honduras específicamente en materia de transparencia y de rendición de cuentas.

ARTíCULO 39.- VIGENCIA. La presente Ley entrará en vigencia veinte (20) días después de su publicación en el Diario Oficial La Gaceta, a excepción de los Artículos referentes a la garantía del Hábeas Data, los cuales entrarán en vigencia una vez sea ratificada las reformas correspondientes del texto constitucional. Queda sujeta a la presente normativa, únicamente la información pública que se genere a partir de la vigencia de esta Ley.

Dado en la ciudad de Tegucigalpa, municipio del Distrito Central, en el Salón de Sesiones del Congreso Nacional, a los veintisiete días del mes de noviembre de dos mil seis. 


\section{ROBERTO MICHELETTI BAÍN PRESIDENTE \\ JOSÉ ALFREDO SAAVEDRA PAZ SECRETARIO \\ BLANCA EDITH RIVERA SECRETARÍA ALTERNA}

Al poder Ejecutivo.

Por Tanto: Ejecútese.

Tegucigalpa, M.D.C., 30 de diciembre de 2006.

JOSÉ MANUEL ZELAYA ROSALES

PRESIDENTE DE LA REPÚBLICA

El Secretario de Estado en los Despachos de Gobernación y Justicia

JORGE ARTURO REINA IDIÁQUEZ 


\section{ANEXOS}

Diario Oficial La Gaceta, 17 de julio de 2007

Reformas a la

\section{Ley de Transparencia y Acceso}

a la Información Pública

\section{Decreto Legislativo No. $64-2007$}

\section{EL CONGRESO NACIONAL,}

CONSIDERANDO: Que Honduras es un Estado de Derecho en donde los funcionarios son depositarios de la autoridad, responsables legalmente por su conducta oficial, sujetos a la Ley y que tienen la obligación de cumplir sus funciones con eficiencia, ética y responsabilidad social;

CONSIDERANDO: Que la transparencia y la rendición de cuentas son garantías para un mejor desempeño del servidor público y del gobierno en general y, además, condiciones necesarias para una efectiva participación ciudadana en la construcción de una auténtica democracia;

CONSIDERANDO: Que el derecho de acceso a la información pública es garantía de transparencia para que los ciudadanos puedan fiscalizar y exigir cuentas a los servidores públicos, a cada paso del proceso y en cualquier momento, y, además, constituye un medio eficaz contra la corrupción;

CONSIDERANDO: Que cuanto mayor sea el conocimiento de los ciudadanos sobre la acción pública, mayor será su participación en la toma de decisiones y su confianza en la función gubernamental; 
CONSIDERANDO: Que el pueblo hondureño tiene el derecho de acceso a la información, así como a la transparencia y rendición de cuentas de los servidores públicos.

CONSIDERANDO: Que el Estado ha ratificado la Convención Interamericana Contra la Corrupción en la cual se reconocen expresamente estos derechos.

\section{POR TANTO,}

\section{DECRETA:}

ARTíCULO 1.- Reformar los artículos 3 numerales 1) y 8); y, 32 párrafo primero; así como adicionar el numeral 11) al Artículo e incorporar el Artículo 32-A, a la LEY DE TRANSPARENCIA Y ACCESO A LA INFORMACIÓN PÚBLICA, contenida en el Decreto No. 170 - 2006 del 27 de noviembre del 2006, que literalmente dicen:

ARTíCULO 3.- DEFINICIONES: Para los efectos de la presente Ley, se entiende por:

1) TRANSPARENCIA: El conjunto de disposiciones y medidas que garantizan la publicidad de la información relativa de los actos de las instituciones obligadas y el acceso de los ciudadanos a dicha información;
2)...;
3)...;
4)...;
5)...;
6)...;
7)...;

8) SERVIDOR PÚBLICO: Cualquier funcionario o empleado del Estado o de cualquiera de sus entidades, en todos sus niveles jerárquicos, incluidos los que hayan sido seleccionados, 
nombrados, contratados o electos para desempeñar actividades o funciones que sean competencia del Estado, de sus entidades o al servicio de ésta, incluyendo aquellas personas que las desempeñen con carácter ad-honorem;

ARTíCULO 11.- FUNCIONES Y ATRIBUCIONES DEL IAIP. EI IAIP tendrá las funciones y atribu-ciones siguientes:
1)...;
2)...;
3)...;
4)...;
5)...;
6)...;
7)...;
8)...;
9)...;
10)...;

11) Garantizar que se publique la información que debe ser difundida de oficio según el Artículo 13 de esta Ley.

ARTíCULO 32.- DEPURACIÓN. Cada institución pública está en la obligación de conservar y custodiar la información pública, incluyendo la reservada, obtenida o generada con motivo del cumplimiento de sus funciones, mientras conserve valor administrativo o jurídico o en su defecto, por un período no menor de cinco (5) años, se exceptúa de esta regla la información clasificada como reservada la cual sólo podrá ser depurada, transcurrido un año después de vencido el período durante el cual se mantuvo en reserva.

ARTíCULO 32-A.- INFORMACIÓN PÚBLICA ANTERIOR A LA LEY. La información pública anterior a esta Ley, no podrá ser destruida, alterada ni cambiada bajo ninguna circunstancia so pena de las sanciones que la Ley establece.

ARTíCULO 2.- El presente Decreto entrará en vigencia a partir del día de su publicación en el Diario Oficial La Gaceta. 
Dado en la ciudad de Tegucigalpa, municipio del Distrito Central, en el Salón de Sesiones del Congreso Nacional, a los veintiocho días del mes de mayo de dos mil siete.

\section{ROBERTO MICHELETTI BAÍN \\ PRESIDENTE \\ JOSÉ ALFREDO SAAVEDRA PAZ \\ SECRETARIO}

\section{ELVIA ARGENTINA VALLE VILLALTA \\ SECRETARIA}

Al poder Ejecutivo.

Por Tanto: Ejecútese.

Tegucigalpa, M.D.C., 21 de junio de 2007. 